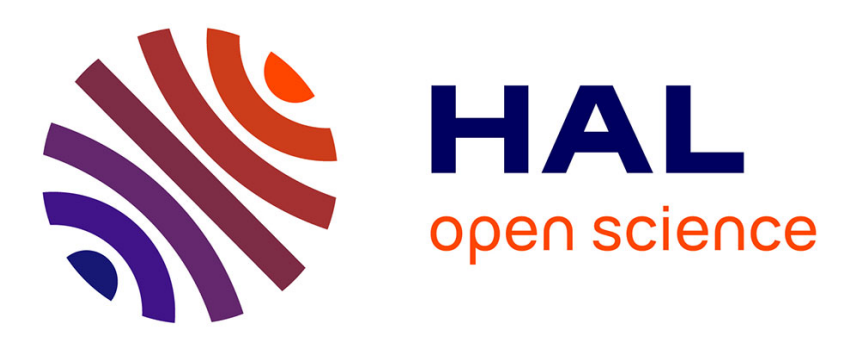

\title{
INHOMOGENEOUS PROPERTIES OF IONIC SEMI-SPIN-GLASSES STUDIED BY MÖSSBAUER SPECTROSCOPY
}

\author{
M. Zemirli, Jean-Marc Greneche, F. Varret, M. Lenglet, J. Teillet
}

\section{- To cite this version:}

M. Zemirli, Jean-Marc Greneche, F. Varret, M. Lenglet, J. Teillet. INHOMOGENEOUS PROPERTIES OF IONIC SEMI-SPIN-GLASSES STUDIED BY MÖSSBAUER SPECTROSCOPY. Journal de Physique Colloques, 1988, 49 (C8), pp.C8-917-C8-918. 10.1051/jphyscol:19888417 . jpa-00228609

\section{HAL Id: jpa-00228609 https://hal.science/jpa-00228609}

Submitted on 1 Jan 1988

HAL is a multi-disciplinary open access archive for the deposit and dissemination of scientific research documents, whether they are published or not. The documents may come from teaching and research institutions in France or abroad, or from public or private research centers.
L'archive ouverte pluridisciplinaire HAL, est destinée au dépôt et à la diffusion de documents scientifiques de niveau recherche, publiés ou non, émanant des établissements d'enseignement et de recherche français ou étrangers, des laboratoires publics ou privés. 


\title{
INHOMOGENEOUS PROPERTIES OF IONIC SEMI-SPIN-GLASSES STUDIED BY MÖSSBAUER SPECTROSCOPY
}

\author{
M. Zemirli $\left({ }^{1}\right)^{1}$, J. M. Grenèche $\left({ }^{1}\right)$, F. Varret $\left({ }^{1}\right)$, M. Lenglet $\left({ }^{2}\right)$ and J. Teillet $\left({ }^{2}\right)$ \\ (') UA-CNRS n' 807, Université du Maine, 72017 Le Mans Cedex, France \\ ( $\left.{ }^{2}\right)$ INSA de Rouen, LPCM, B.P. 8, 76131 Mont Saint Aignan, France
}

Abstract. - We have analysed in terms of static hyperfine field distributions the Mössbauer spectra of mixed $\mathrm{Zn}-\mathrm{Mg}$ ferrites. Typical features of semi-spin glasses are observed both in average and locally: in each sample, the relevant data are smeared out in a way which reveals the behavior of the series.

\section{Introduction}

Mössbauer spectroscopy of ferrites provides the advantage of weak quadrupole interactions (high-spin $\mathrm{Fe}^{\mathrm{III}}$ ) and well-defined saturation value of the hyperfine field $\left(H_{\text {hyp }}\right)$; this allows an accurate analysis of $H_{\text {hyp }}$ distributions, easily revealing the variation of the magnetic moments with temperature or applied magnetic field. On the other hand, short-range magnetic interactions lead to highly inhomogeneous magnetic properties, for which the description in terms of magnetic cluster glass [2] may be adequate.

We have studied the mixed spinels $\left(\mathrm{Zn}_{x} \mathrm{Fe}_{1-x}\right)$ $\left[\mathrm{Mg}_{1-x} \mathrm{Fe}_{1-x}\right] \mathrm{O}_{4}$, where ( ) and [] respectively stand for $A$ and $B$ sites. The available compositions, $x=0.6$, $0.7,0.8,0.9$, are close to the percolation threshold of A-B interactions [1], where a re-entrant spin glass behavior is expected.

We summarize here the results [2] of a static analysis of Mössbauer spectra, in terms of $H_{\text {hyp }}$-distribution, depicting the inhomogeneous behavior of weakly coupled magnetic clusters [3]. These clusters originate from the introduction of strong interactions of $A-B$ type, diluted into a matrix with much weaker (and frustrated) B-B interactions. The relevance of such static analysis is supported by the observation that Mössbauer spectra (Fig. 1) in a large range of temperatures consist of superimposed quadrupole and magnetically-split contributions, so that only few iron atoms have their magnetic relaxation time in the Mössbauer window $\left(\approx 10^{-8}-10^{-9} \mathrm{~s}\right)$. This discussion, together with the detailed magnetic study (highfield Mössbauer spectroscopy and magnetization measurements) will be developped in forthcoming papers.

\section{Average Mössbauer data}

Since A and B sites are not resolved in the Mössbauer spectra out of field, the following data re-

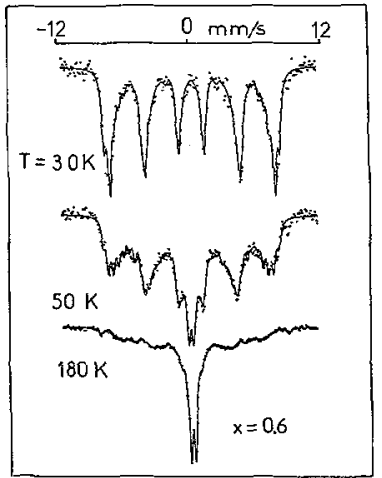

Fig. 1. - Typical Mössbauer spectra fitted by a static discrete distribution of hyperfine fields and a quadrupole doublet.

fer to "average" sites, which are predominently $B$ sites (from $80 \%$ to $95 \%$ for $x$ ranging from 0.6 to 0.9 , respectively).

From the thermal variation of the measured average hyperfine field $\left\langle H_{\text {hyp }}\right\rangle$, the magnetic phase diagram was established (Fig. 2); the re-entrant transition is detected by a kink [4] on $\left\langle H_{\text {hyp }}(T)\right\rangle$ curve. The disappearence of the magnetic pattern is interpreted, as usual, rather in terms of clusters blocking than in terms of a true Curie transition.

\section{Inhomogeneous analysis}

Here we follow a static analysis previously described [5], for which each cluster type is characterized by the thermal variation of a hyperfine field $H_{n}$. Provided the curves $H_{n}(T)$ do not intersect, each cluster can be characterized by the probability $Q_{T}\left(H_{n}\right)$ cumulated from 0 to $H_{n}$.

Sections of the surface $Q=f\left(T, H_{n}\right)$ by the planes $Q=Q_{i}$ yield the thermal variations of the hyperfine

\footnotetext{
${ }^{1}$ Present address: INES Génie Civil, Université de Tizi-Ouzou, 15000 Algeria.
} 


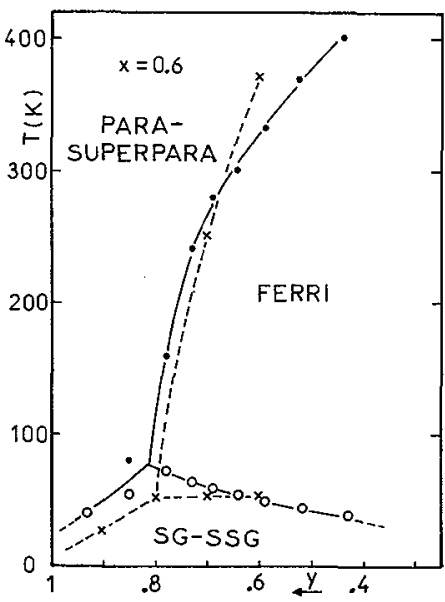

Fig. 2. - Magnetic phase diagram obtained from average Mössbauer data (dashed line) and from inhomogeneous analysis (full line) of sample $x=0.6$.

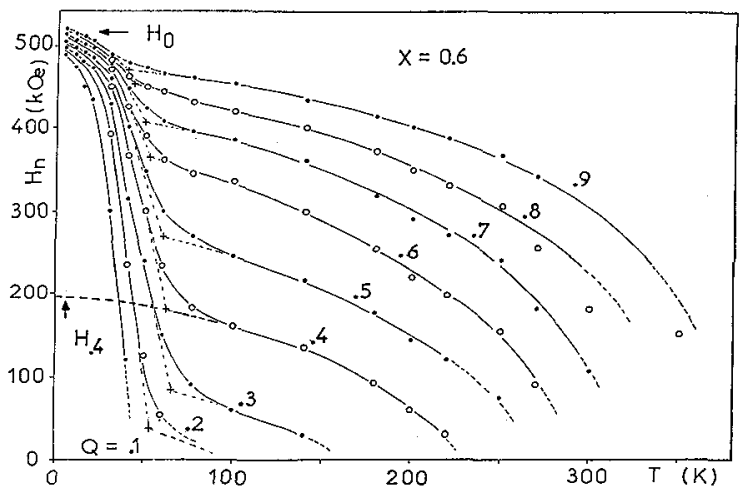

Fig. 3. - Set of curves $H_{n}(T)$ for various values of the labelling parameter $Q$. The determination of the canting angle is shown for $Q=0.4:|\cos \theta|=H_{0.4} / H_{0}$.

fields of the clusters labelled by the $Q_{i}$ (Fig. 3). The data treated this way show the presence of a kink on each curve; the canting angles are obtained from the ratio $H_{i} / H_{0}=|\cos \theta|$ (according to [4]) where $H_{i}$ and $H_{0}$ are extrapolated values at $0 \mathrm{~K}$ of the hyperfine field, in the high and low temperature range, respectively. They vary from almost 0 to $90^{\circ}$, following the labeling parameter $Q$. Also, the re-entrance temperatures vary according to $Q$.

It is likely that the labeling parameter follows the strength of the magnetic coupling of the various clusters, which depends on the local density of strong A-B interactions, i.e. the local density of tetrahedral irons. We have calculated, as a function of $x$, the correlation $Q-y$, where y is a "local" zinc content deduced from a binomial analysis of the magnetic first-neighbours [2] so that the phase diagram could be built up again, in the $T-y$ plane, from the data of a single sample. This is done in figure 2 for the data of $x=0.6$ (full line); it roughly agrees with the former (dashed line).

High field Mössbauer study [2] confirms this inhomogeneous magnetic properties, with a spread of canting angles similarly correlated to the labeling parameter $Q$.

The sensitivity of the magnetic structure to local composition (and to external field [2]) probably originates from the frustration of the $B$ sub-lattice.

The compositions near the antiferromagnetic structure $(0.8<x<1)$ are under study.

[1] Scholl, F. and Binder, K., Z. Physik B 39 (1980) 239.

[2] Zemirli, M., Thèse de Doctorat de l'Université du Maine, France (1988).

[3] Hartmann-Boutron, F., Ait-Bahammou, A. and Meyer, C., J. Phys. France 48 (1987) 435.

[4] Campbell, I. A., Senoussi, S., Varret, F., Teillet, J. and Hamzic, A., Phys. Rev. Lett. 50 (1983) 1615.

[5] Varret, F., Gerard, A. and Imbert, P., Phys. Status Solidi $B 43$ (1971) 723. 